\title{
Learning Futures with Mixed Sentience
}

John C. Bricout, Ph.D.

University of Texas at Arlington

johnbricout@uta.edu

Bonita B. Sharma

University of Texas at Arlington

Bonita.sharma@mavs.uta.edu

Paul M.A. Baker

Georgia Institute of Technology

paul@CACP.GATECH.edu

Aman Behal

University of Central Florida

abehal@ucf.edu

Lotzi Boloni

University of Central Florida

lboloni@eecs.ucf.edu

The Authors Gratefully Acknowledge the National Science Foundation, CHS Medium and the Wireless Rehabilitation Engineering Research Center, Funded by the National Institute on Disability, Independent Living and Rehabilitation Research. 
Attaching a particular date or event to the beginning of a future; or perhaps as Winston Churchill might have it, the end of the beginning, is always fraught. In 1996 IBM's Big Blue supercomputer defeated the reigning chess master, Gary Kasparov - presumably by learning and executing superior strategies. Early in 2016 Alpha Go beat three-time European Go champion Fan Hui, and in that same year Google took on the mantle of a "machine learning company first" to acknowledge its commitment to deep machine learning and artificial intelligence (AI) (Backchannel, 2016). This is consistent with the branching possibility of a future envisioned by noted computer scientist Pedro Domingos, whose book Master Algorithm describes the paradigm shift that machine learning is bringing about, with an emphasis upon the learning that can take place without human intervention, or to riff from an Alfred North Whitehead quote in the book's leaf - thoughts without (humans) thinking about them. The goal of this paper is to explore an alternate future for human and machine intelligence, one in which human and machine learners together inform "operations" or actions in a reciprocal and mutual fashion, with the particular goal of augmenting human capabilities; especially those of people with disabilities. These augmented capabilities can be made possible through robotics integrated into a learning community with humans as co-sentient entities, changing the way people with disabilities, and indeed people generally, live in the world. This foreshadows a paradigm shift, enabling mutually constructed human-machine learning encounters with the external world. While such a future is yet over the horizon, we can see incipient forms of robot-human collaborations, and nascent learning networks. This paper will review the roles played by assistive technologies in augmenting learning and action for people with disabilities, while also describing current and emerging trends in augmentive technologies and artificial intelligence, with a special emphasis upon socially assistive robotics (SAR). SAR is posed as a technology can augment the 
capabilities of people with disabilities by acting in concert with human users in learning networks. The paper then considers three possible scenarios for the development of human-robot learning communities, contingent upon how human users engage the networking capacity of those communities. Finally, the ethical implications of human-robot learning communities in each scenario are assessed in the light of how user capabilities are augmented.

In the past, access to formal learning (i.e., education) for people with disabilities was primarily a private matter, largely out of the public legislative sphere, until section 504 of the Rehabilitation Act of 1973 mandated "free appropriate education" for each qualified student with a disability in the United States. In the decades since, great strides have been made in ensuring accessible public education for people with disabilities in the U.S., as well as accessible platforms for information sharing and learning online, bolstered by the World Wide Web Consortium (W3C) a global body aimed at ensuring open standards online. The shift has been from accessible learning as a private matter, to a public concern. As we consider probabilistic futures, we anticipate yet another shift from the public arena to self-organizing learning communities. This shift mirrors trends in the general population, as life-long learning through multiple channels, online and face-to-face, becomes the dominant paradigm (Brady, Cardale, \& Neidy, 2013). Meanwhile, technology provides the tools and media for customized learning trajectories and long-tail solutions to unique learning needs. What is particular to learning and people with disabilities is the prominent role of accessibility at the group level, and 'usability' (or user-specific adaptations) at the individual level (Seale, 2006). In recent years we have witnessed a leveling effect of technology as capabilities that once resided in individuals are now 'embodied' in machines and networks that augment the physical, cognitive, motor and sensory capacity of all humans (e.g., Campbell, 2006). Nonetheless, people with disabilities have a 
distinct trajectory in this augmentation narrative as they aspire to a future in which their capabilities are not only deemed functionally equivalent of others' but also normatively equivalent, whatever its expression in terms of form (Ward, Moon \& Baker, 2012).

. Perhaps the most interesting thing about possible futures for human learning as a whole is that the underlying learning dynamic may not reside wholly, or even chiefly among "us." Nonhuman learners - namely networked robots and influential software agents (in the guise of social agents) - may play key roles in the future of learning. In recent years we have witnessed a progressive shift in the locus of learning between humans and robots from human-centric to robot-centric learning. A 'mixed' learning environment is the result in which either humans or robots may lead, each equipped with degrees of sensory awareness and/or consciousness (i.e., sentience) such that reciprocal learning is feasible. Human and robot sentience need not be equal nor equivalent, but simply complimentary, in the scenario of mixed sentient learning futures. Humans have provided a model on which robots can base their learning trials (Thomaz \& Breazeal, 2008), robots have also learned how to acquire new task knowledge in collaboration with humans (Peternel, Petric, Oztrop \& Babic, 2014), but most provocatively humans are now learning from robots in a fashion at least equal, if not superior to learning from other humans (Mazzoni \& Benvenuti, 2015).

Digital technologies have rendered new opportunities for learning that transcend barriers of time and space. Technology can be used to create a barrier-free learning environment conducive to knowledge acquisition and skill development. For people with disabilities technology-enabled learning holds the promise of greater workforce participation, social interaction, problem-solving skills and educational success. Robots have the potential to serve an assistive role in human learning, whether by providing information (i.e., Moran, Bachour \& 
Nishida, 2015), assisting in task acquisition and performance (i.e., Hashim \& Mahamood, 2014), or behavior modeling (i.e., Rabbitt, Kazdin, \& Scassellati, 2014). Researchers are grappling with how to make robots more engaging to people, including people with disabilities (Alonso-Martin, Castro-Gonzalez, Luengo, \& Salichs, 2015), holding out the possibility that people who use robots will not be ostracized, if not directly addressing the potential for decreased social participation with increased robot presence. The possibilities for the synergistic effect of humanrobot learning exchanges will depend upon the nature of the learning communities, their constituents' capabilities, and their relationship of the communities to broader trends in learning.

Recently the notion of 'agency' or autonomous action in the surrounding environment has been extended to robots and software agents, recasting them as 'social agents' (Holz, Dragone \& O’Hare, 2009; Mackenzie \& Watts, 2011). In this framework, robots can participate as both independent and interdependent elements in active learning scenarios, whether part of semi- or fully autonomous technological systems (Steinert, 2014). Robots are, by definition, autonomous inasmuch as they act independently in response to some admixture of their programming and environmental demands. One vector for increasing robot autonomy aims towards the development of an artificial intelligence (AI), equivalent to human intelligence but of distinctly machine origin and nature and freed of programming constraints. A parallel vector aims towards augmenting existing (human) capabilities and thus supplements, rather than substitutes for, human intelligence. Both AI and augmentation approaches are advancing robot and social agent capacity for engaging humans in learning, with the difference not always acknowledged, even when a single project may incorporate both aims (Markoff, 2015).

\section{Learning Environments}


Both augmentative and artificial intelligence approaches must be acknowledged as they are likely to shape learning community future. Attempts to presage a 'winner' or even to argue the need for a sole victor, creates a needless binary when each can be purposed for different roles in pursuit of a common goal. Having said that, for people with disabilities in particular augmentation (leveling the playing field) is more consistent with the long-term aspirations of full citizenship (societal participation) than AI. Artificial intelligence tips the balance away from human learners who will be relatively deficient and thus relegated a secondary role in the learning community. In the context of robots serving people with disabilities the goal is not the development of artificial intelligence that obviates the need for human engagement, but rather the augmentation of human capabilities through a user-robot partnership.

Robotics. Socially Assistive Robotics (SAR) occupies the space of an engaging 'social agent' owing to the robot's unique relationship with human users. SAR blends the assistive roles of robots that aid users, with socially interactive robots that engage users socially (Anzalone, Bouccenna, Ivaldi \& Chetouani, 2015). SAR merges characteristics of robots that aid people in their performance, daily activity and life goals (i.e., assistive) with targeted social interactions (i.e., social) mediated by the robot's ability to respond to user's emotions, touch and participate in social learning (Blackman, 2013; Rabbitt, Kazdin, \& Scassellati, 2014; Tapus, Mataric \& Scassellati, 2007; Tapus, \& Mataric, 2008). It is not difficult, by extension, to anticipate that SAR will be able to serve as the ideal one-on-one tutor: patient, infinitely adaptable, and act as a bridge to society at large (Singh, Karanam, \& Kumar, 2013). SAR need not be human-like to engage humans socially, emotionally or instrumentally. They can resemble animals, abstract objects or even human appendages (i.e., limbs, exoskeletons) and take part in larger network of 'intelligent agents’ such as wearable computing (Mad, Wade \& Johnson, 2010; Malik, Hanapiah, 
Rahman, \& Yussif, 2016). As the key attribute is that the robot assists with social interactions, rather than purely physical ones, a robot like the Wheelchair Mounted Robotic Arm (WMRA) for manipulating objects, in a learning system architecture that includes users and robots in exchanges that are social and informational (sharing arm and user knowledge), may be considered SAR, particularly as the WMRA's repertoire adapts to the user's. Several authors of this article (Bricout, Sharma, Behal, Bolini) are currently engaged in a funded research project with that very goal: to create a robot-human learning network using WMRA.

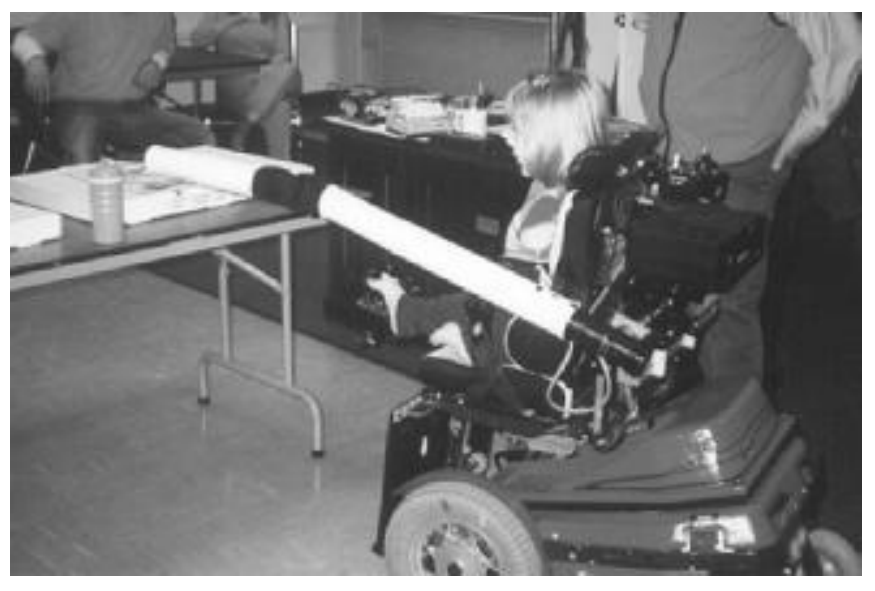

\section{Wheelchair-mounted Robotic Arm}

SAR offers a unique approach for significantly increasing the learning capabilities and the social participation of people with disabilities (Keizer, Foster, Wang \& Lemon, 1q 2014). People with physical disabilities have benefited from engaging with SAR that offers greater independence of movement and provides emotional support, especially in the guise of 'companion robots' taking on roles that have traditionally been occupied by attendants, caregivers and/or pets (Pearson \& Borenstein, 2011; Tapus, et al., 2007; 2008). Individuals, especially children on the autism spectrum disorder, may benefit from the application of SAR as a diagnostic approach (Pearson \& Borenstein, 2011; Tapus, et al., 2007). The leading edge of SAR development has robots learning and predicting human behavior (Blackman, 2013; Keizer, 
Foster, Wang \& Lemon, 2014). Research has demonstrated that physical attributes of the SAR (i.e., size, shape, etc.) have an impact on both the user's expectations of the robot's role and the level of comfort with the robot (Feil-Seifer, 2014; Rabbitt, Kazdin, \& Scassellati, 2014). The robot's embodiment and physical presence will have an impact on user social engagement of the user, but so too will user characteristics predisposing the human to favor functionality or form (Moran, Bachour, \& Nishida, 2015).

\section{Capability Building Technologies}

For people with disabilities SAR has the potential to augment not only the capacity to perform discrete tasks, but also multi-faceted competencies, such as those required for paid, competitive employment. SAR falls within the larger category of assistive technologies. Assistive technologies (AT) refer to technological artifacts such as devices, systems, and equipment that maintain or improve the functional capabilities of people with disabilities in a manner similar to informational technologies or instructional technologies intended for the general population (Edyburn, 2004). This has led to extensive discussions on the boundaries of AT in a world characterized by technology that augments human performance. The best way to describe AT and its sister technologies may be in terms of what Edyburn (2004) refers to as "technology-enhanced performance" - whether the reference point for the enhancement is "normal," "unaided" performance, or performance deficits ascribed to the interaction of people with disabilities and their environments (Edyburn, 2004). "Augmented performance" is the term of art for extended human capabilities achieved through the aid of technology, including SARenhanced capabilities. It also provides an explicit framework for understanding how SAR can alter user life trajectories beyond the immediate effect of a device (robotic or otherwise) acting directly upon the user's environment. In the context of augmented performance the user's 
capabilities are enhanced as the user learns to better navigate complex tasks, often times with the assistance of others in the environment who help perpetuate and extend the learning.

SAR can provide augmented capabilities to a broad spectrum of people with disabilities. Recent advances in robotics have involved robots adopting human-like behaviors, such as motion patterns (Kodagoda, Schestedt, \& Dissanayake, 2016), as well as in giving and taking feedback with humans in a collaborative learning context (Castro-Gonzales, Malfaz, Gorostiza \& Saliches, 2014; Kartoun, Stern \& Edan, 2010). On the basis of these advances we anticipate several possible applications of SAR to augment the capabilities of people with disabilities. For the purposes of illustration let us consider three broad categories of disability: (1) intellectual disabilities, (2) cognitive disabilities, and (3) physical disabilities. Brief hypothetical applications will serve to illustrate the potential role of SAR in providing augmented capabilities.

First, a workplace scenario involving people with intellectual disabilities in the form of robotic co-workers. Co-robots are being developed that will work alongside with humans in the workplace. The intention is for these robots to be genuine co-workers and operate on a social level as well as a task-performance level (Lasota \& Shah, 2015). Critical to the development of true co-worker robots in industrial settings will be improved situational awareness because of heightened safety issues (Shackleford, Hong, Saidi \& Shneier, 2016). For robots operating in an assistive role, adapting the robot's motion planning to mirror that of a human in a collaborative task in the guise of a teammate than with a standard robot (Lasota \& Shah, 2015). The notion of a robot co-worker, at least in information-rich occupations, such as library work, appears to be gathering interest (Sanborn, 2015). For people with disabilities, a recent review article found generally positive anticipation of service and social robots, although accessibility (affordability and design) as well as labor competition were raised as concerns (Wolbring, 2016). 
A proven employment approach for workers with intellectual disabilities is supported employment in which both supervisors and co-workers provide the supported worker with additional guidance, feedback, instruction and supervision based on a careful analysis of job environment and demands (Wehman, Chan, Ditchman, \& Kang, 2014). SAR could provide coworker supports, assisting the supported worker with task sequencing cues, performance feedback and concrete assistance. The supported worker would retain some of these new patterns of performance being modeled by the robot, while others would be learned through reinforcement.

Second, let us consider the role of SAR in the context of cognitive disabilities. For individuals with cognitive disabilities, say older adults with poor memory, SAR could provide medication, as well as monitor vital signs and prompt action, when critical levels of dysfunction are detected through wearable computing devices (wearables) that collect health status data (Huschit \& Clune, 2012). Depending upon their level of cognitive decline, users would not be passive in the information exchange and decision making process, but rather provide their own feedback and acquire (i.e., learn) new behavior patterns through reinforcement learning (Moyle, Cooke, Beattie, Jones, Klein, Cook, \& Gray, 2013). In the instance of high cognitive impairment studies (i.e., studies of robot interventions with dementia) are likely to find substantial amounts of missing data, with severe limitations on self-report data that other robotic intervention researchers use (i.e., Moyle, et al., 2013). Structured activities for patients with dementia were found to reduce dementia-related behaviors when the activity involved an SAR (Moyle, et al., 2013). Even for older adults in cognitive decline for whom there is no definitive treatment a 'transfer effect' is possible following cognitive training (Kim, Jeon, Kwon, et al., 2015). Perhaps because of the novelty and other factors, robot-assisted, multi-domain cognitive training was 
found in a recent study to attenuate cortical thickening (associated with cognitive decline) more than either traditional (human-delivered) cognitive training or the control (no training) condition (Kim, et al., 2015)

Third, for people with physical disabilities robotic limbs and even exoskeletons have the potential to far extend the user's capabilities. Beyond the direct effects of performanceenhancing robotics SAR in this context will engage the user's capacity to learn, and expand both his/her repertoire of physical capabilities. Perhaps the greatest potential lies in networked human-robot pairs and ultimately user-robot groups designed to exchange queries, information and knowledge-building. It is in the context of this latter case that authors of this article are conducting research aimed at developing a learning network of wheelchair mounted robotic arms (WMRA) in which humans and robots collaborate to augment user capabilities. This is will serve as our archetype for envisioning SAR human learning networks in the futures context of larger communities with the same or similar learning needs and goals.

\section{Futures Approaches}

The use of SAR to augment the capabilities of people with disabilities is an emergent and burgeoning field of research and practice. The history of robots as assistive technology to aid people with disabilities complete tasks dates back three decades to 1986, however, the notion of 'assistive robotics' balancing robot learning with human learning appears to be more recent about half as long, dating to 1999 (Cook \& Cavales, 1999), with socially assistive robotics articulated only in the past decade. A short history, such as this, renders insights into the future by extrapolation especially problematic. Fortunately, as we ponder how this emerging technology may play out for people with disabilities we can avail ourselves of the tools and perspectives of futures (plural) studies. Some authors point as far back as 1589 and Luis de 
Molina's work "Conditional future contingents" as a seminal document for futures thinking (Sardar, 2010).There seems to be broad consensus around the roots of contemporary future studies in World War II, during which entities such as the Rand Corporation and others tied strategic planning analysis to projections of the future with a focus on predictions for military and economic purposes (Kuosa, 2010; Krawczyk \& Slaughter, 2010). In the decades since the recognition has come that there is no single 'future' - but rather, some number of possible 'futures'. 'Foresight' approaches address the need for strategic management, public policy and decision making in the context of diverse and competing futures (Habeggar, 2010; Konnola, Scapolo, Desruelle, \& Mu, 2010). Societal challenges are not the focus of this paper, hence we rejoin the futures scholarly conversation with more generally through the portal of scenario planning.

As 'the future' is indeterminate, futures studies and futures methods steer us away from simple extrapolations to considerations of systematically designed scenarios as an antidote to tunnel vision and as highly sensitive environmental scans that have the potential to shift paradigms (Jetter \& Kok, 2014; Jetter \& Schweinfort, 2010). Scenarios have been described as 'sensemaking' drawn from diverse individuals each with distinct mental models and crafted by a scenario planner (Jetter \& Schwienfort, 2010). Habeggar suggests a visual illustration of the scope of futures scenarios in terms of a cone, the defined by 'potential' with 'possible futures' on a slightly different alignment but equal in scope. The possible exceeds the plausible, with the preferable occupying a smaller space adjacent to the probable, which constitutes a kind of bull's eye. Possible futures contain all imaginable futures, perhaps even exceeding our current scope of knowledge and unconstrained by likelihood. Plausible futures fall within the limits of our current knowledge and have a reasonable likelihood of occurring. Probable futures encompass 
extrapolations and have a high probability of occurring, while preferable futures are informed by subjective values and judgments (Habeggar, 2010).

As we consider possible futures of SAR we are largely bound by the plausible, having focused on augmented capabilities readily conceivable with our current state of knowledge, eschewing for instance an artificial intelligence (AI) focus that would carry us substantially into the unknown and possible futures of indeterminate probability. Meanwhile, the brief history of SAR has already eliminated a probable scenario approach because of a paucity of data for extrapolation. The degree to which each of the plausible scenarios is preferable will also be established to reflect the emphasis upon self-determination, human rights and social justice for people with disabilities as a group recognized by the United States (from a minority rights perspective) and from the United Nations (from a human rights perspective) as warranting special protections to ensure full 'citizenship' and participation in society (Wolbring, 2015).

Emergent Trends. SAR can contribute to the user's awareness, perceived choices and freedom of action - his or her capabilities in the language of scholar and ethicist Amartya Sen (Coeckelbergh, 2010; Toboso, 2011). Augmentive technologies, inclusive of SAR and other computer-mediated social agents, have the potential to synthesize the learning of human and non-human network elements (Coeckelberg, 2010). This would be to the benefit of people with disabilities' access to broader, independent networks from which resources can be drawn, and hence, the sphere of their capabilities.

Emergent trends in augmentative technologies point to at least three inclusive futures with accessibility, cross-cutting digital and physical spheres of learning and action. Digital communities populated by SARs and human users can create joint spaces for learning and exchange, unbound by physical constraints. In this scenario SARs dialogue with users in 
communities of interest, networked within broader wireless connections in the digital sphere, transforms access to learning, and ultimately social goods. This collaborative dialogue allows informational, relational and experiential ties to emerge from the networked capabilities of a barrier-free SAR-user community. In broad terms, the inclusivity flowing from this learning collaboration offers new interaction patterns, changing perceptions of self, others, community, and policy discourse.

Socially assistive robots are a sub-set of robots that work and live alongside people, socalled co-robots. Companion robots constitute another subset that may or may not assist with social interactions as opposed to physical ones. The robots in question vary a good deal in size and shape. They may or may not be anthropomorphic, looking very much like a person or humanoid, having human features (four limbs, torso, head, feet, eyes, mouth). The humanoid robots can be quite small and toy-like, such as Nao (below, center). Socially assistive robots do not need to be humanoid to elicit the all-important social engagement; they can be shaped like a dog (i.e., Aibo) or like a cute toy-like presence like Mamoru (below, right). Depending upon the users with whom they are interacting and the role they are to play different robots will elicit different levels of engagement. Larger robots are generally perceived as more threatening but smaller robots may be discounted as children's toys (Wu, Fassert, \& Rigaud, 2012).
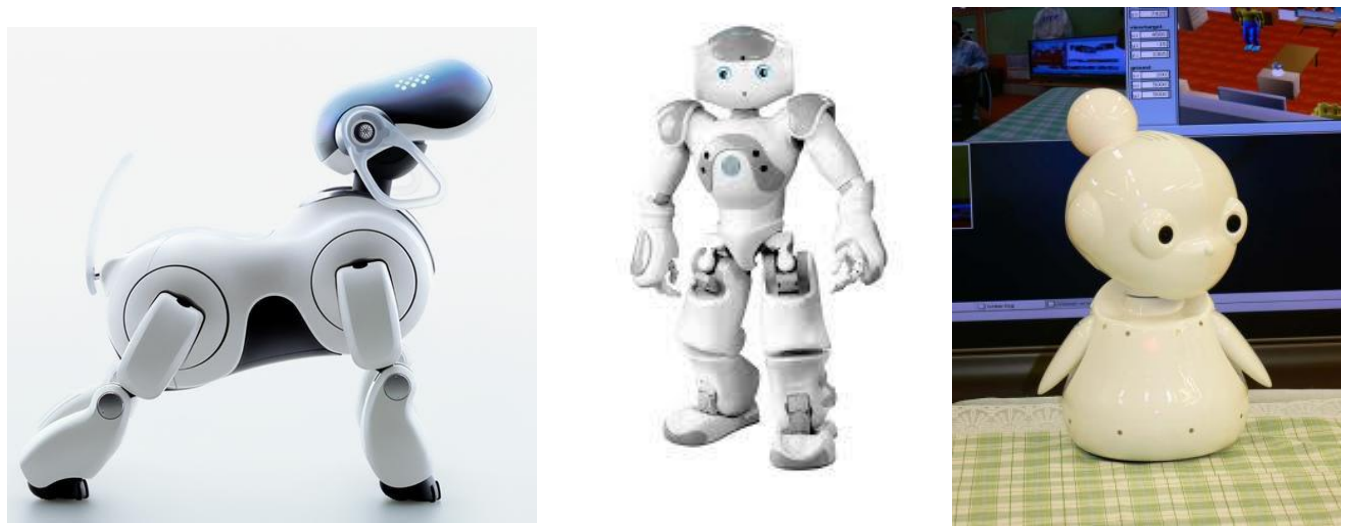
Because of the explicitly social nature of human-robot interactions with SAR there is an opportunity to create a community in which there is not only two-way exchange but also reciprocal relationships, inclusive of emotional attachments. In other words, users may come to see that the SAR has as much need for him or her as vice versa. The SAR becomes another social actor, capable of being acted upon as much as acting. Rather than being an error-free, super-human entity, SAR, will be designed, as having "humanizing" characteristics, (e.g. "flaws" or quirks), and thus perceived by users as having vulnerabilities, perhaps not the same as humans, but on a par with them. In the current day, humanoid (anthropomorphic) robots may evoke skepticism and even feelings of discomfort at the point at which artificial beings appear almost like natural ones - the so-called 'uncanny valley' - raising discomfiting questions of (human) identity, rights and norms (Mara \& Apel, 2015). However, for social learning to take place there must be sufficient semblance of shared non-verbal gestures, communication and imitation, triggering the social facilitation response in which the presence of another can actually enhance performance (Moran, Bachour, \& Nishida, 2015). This suggests that once humanoid robots, properly designed for social interaction, become more prevalent, learning human-robot pairs will engage in situated, perhaps even culture-specific knowledge exchanges spurred by perceived similarities (Mara \& Apel, 2015). In this vein the user-robot pair bond is scalable to networks of humans and SAR, with the possibility of both shared and non-shared learning norms and community-specific behavioral cultures. The human-robot transactions will vary with the behavioral norms characterizing the robot-human relationships as well as the user disability (Anzalone, Boucenna, Ivaldi \& Chetouant, 2013). The balance of learning interactions will thus be dynamic and situational, rather than a value-free, information-neutral series of exchanges. 
This represents design intriguing challenges along several different dimensions, including ethical dimensions which will be explored later.

The pace of pervasive technology implementation and the growing use of assistive technology, including, quite recently, SAR, have overtaken society's adaptation to the emergent ethical challenges of accessibility in the $21^{\text {st }}$ century. Existing approaches in the design and implementation of assistive technology tend to focus on the properties of the technology and/or the properties of the user, rather than the properties of the relationship between them. Assistive technologies, such as SAR and other intelligent agents, are increasingly networked and become part of the users' social schema which needs to be a locus of both practical and ethical design considerations. As human-machine networks take on the properties of community: collective identity, a sense of belonging reciprocity, interdependence and an in-group bias, the rights of each community, as well as its constituents, must be taken into account. Each community may assert communal rights; for example, the right to voluntarily engage (or disengage), as well as to assert confidentiality and self-determination within group.

\section{Human and Other Intelligence Communities}

The emergent SAR-user communities depend upon the larger ecology of social, economic, political and technological spheres in which they are nested. There are several sociotechnical trends that set the stage for possible futures with SAR human learning communities. One such trend is the use of SAR to augment the capabilities of people with disabilities in collaboration with other humans, for example: children with cognitive disabilities (Hashim \& Mahamood, 2014), and people with cerebral palsy (Malik, Yussof, Hanapiah, \& Anne, 2014). Some futurists view augmenting technology, such as augmented reality technologies, integrated into the store of human capacity and functioning in the next few decades (Kurzweil, 2005). As 
augmentation of user capabilities to the limits of unenhanced human capacity - and beyond becomes more commonplace SAR-human learning communities for people with disabilities will likely proliferate as one of a variety of augmentation platforms for extending user capabilities.

People with disabilities are a heterogeneous group of people, and the diagnostic categories/labels into which individuals are placed based on functioning may be overlapping or ill-defined, in part due to environmental factors, accommodations, assistive technologies and compensatory strategies or other sources of remediation that alter the user's capacities. For the present discussion we will largely refer to people with disabilities generally, with a few 'drilldown' exceptions for the purpose of better illustrating the roles of user, SAR and social agents in a given community of learners. As specific SAR technologies for people with disabilities are developed dyadic robot-user pairs are often used to develop a suitable graphical user interface (GUI) and to calibrate the robot's actions. Depending on the goal of the interaction and the type of user responses that are of interest video recordings will typically be made and the interactions rated. For the purposes of this paper it is important to note that the robot-human learning communities could be quite diverse in terms of the human users (people with disabilities) groups thanks to universal design features described later. Although beyond the scope of the present paper, the issue of how learning communities might be configured for people with particular types of disabilities is certainly worth considering.

SAR-user learning communities are arguably another permutation of online coordinated peer-to-peer exchanges for the benefit of collaborative access to valued social goods - in this case information enhancing capabilities - and sustainability of the user community. Thus, SARuser communities can be viewed as emerging along a wave front of online collaborations; a special case of online communities, networked to varying degrees of permeability with other 
online communities, rather than as a specialty assistive technology with limited functionality and fixed boundaries. This trend towards cooperating online communities for augmenting the capabilities of each, has created a space for SAR-user learning communities in the future. Another influential trend is closely bound to the rise (or transcendence) of social media and the online communities of interest they form across every conceivable geopolitical, ethnic, cultural and societal boundary. In this trend we see the alignment of multiple social identities behind a common cause; whether a driving force or simply one of several guiding frameworks for coordinated and/or collaborative action. These communities of interest will inevitably include defining memberships for users with disabilities and their SAR companions. These two trends in tandem: augmentation and online communities of interest will create the space in which humanrobot learning community futures unfold.

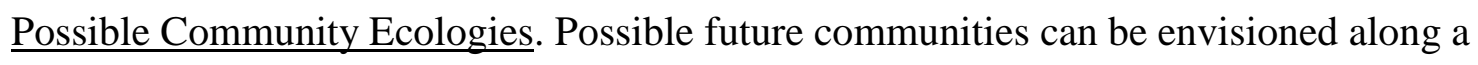
continuum from a relatively 'open ecology' characterized by highly interdependent and coordinated social technologies, seamlessly integrated with smart technologies, to a comparatively 'closed ecology' of specialized and independent social technologies. Factors influencing the end of the continuum that SAR-user communities will occupy include: marketdriven developments in systems interoperability, policy-driven resource alignments and technology-driven advances in the integration of social agents. Design challenges include the development of suitable immersive environments for conveying complex exchanges of knowledge and information, inclusive of interfaces for human learners to employ all five senses and robot learners to integrate experiential learning in a shared environment, as well as a new set of heuristics not only for designing artificial personalities, but also for assessing and evaluating the new relationships arising from the adoption of SAR. Human robot learning communities will 
share certain common characteristics, regardless of where they fall along the continuum of 'open' to 'closed' ecologies. The 'open'-to-'closed' continuum speaks to the level of integration between learning communities, their capacity for coordination and synergy, rather than the internal architecture of human-robot learning communities which bear the stamp of common elements and basic processes.

We anticipate that human-robot leaning communities will be undergirded by trust amongst the mixed human and robot constituencies. We posit a degree of stability, autonomy and cohesiveness akin to learning organizations. In learning organizations individuals collaborate to create systemic learning processes, which in a climate conducive to interpersonal trust, enables stronger linkages (commitment) to the organization. In this fashion, learning organizations that foster trust appear to also foster stronger member identification and involvement (Song, et al., 2009). We anticipate that human-robot trust will similarly generate enhanced performances through social learning. In this schema, social learning is accessible to SAR - as well as to humans. This process is captured in the conceptual model, below. 


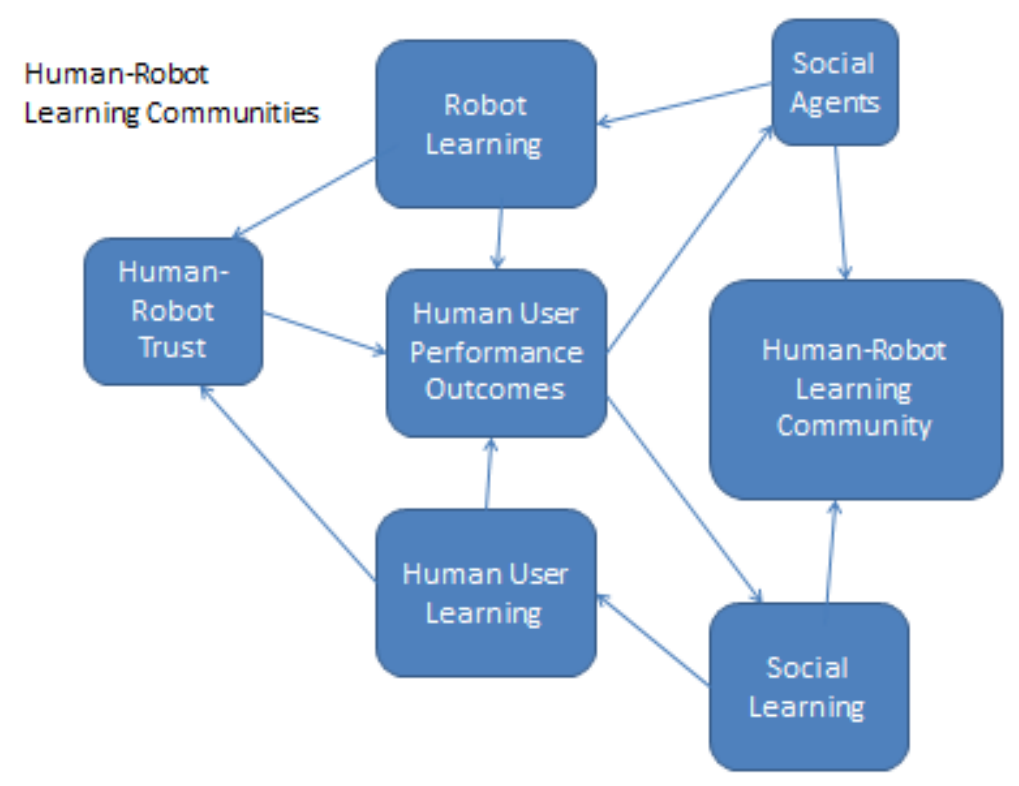

For the purposes of illustration let us imagine that the robot-human learning community is functioning to assist workers with developmental disabilities to get to work independently, and on time, using some admixture of public transportation, para-transit and private vehicles. Contemporary research aimed at problem solving the challenges associated with having individuals with intellectual and/or sensory disabilities have focused on the use of devices with either GPS-loaded devices (Davies, Stock, Holloway and Wehmeyer, 2010) or location-learning tools combined with games-based learning (Brown, McHugh, Standen, Evett, Shopland \& Battersby, 2011). The learning tools serve as social agents, absent the presence of SAR. In future learning communities, SAR will have vast reserves of user-preference knowledge and experience to draw upon and share, not only with their own user but also with other users - and other SAR who are within the learning community circle of trust. Rather than individuals learning how to navigate transportation modalities and routes for work or other activities, aggregates - from dyads to communities - can coordinate to engage collective knowledge and resources for higher- 
order benefits, up to and including, policy changes in the configuration and disposition of transportation. The difference is qualitative, rather than simply a reflection of scale, as the learning communities' collective problem-solving resources will have the potential to bring about disruptive changes to barriers that currently pose significant social problems. For instance, “transportation" problems might be reframed by dialoguing communities as urban design problems best remedied by bringing constellations of work/recreation/civic participation activities to the user rather than vice versa. "How to get there" may be superseded by "how to bring it here", or "how to render 'here' and 'there' meaningless distinctions".

As designers, policy makers and others confront complex social problems in the context of pervasive and ubiquitous technology they will need tools for framing and examining how cooperative interchanges between technology and humans can be leveraged synergistically to solve such problems. For those engaged in increasing the capabilities and social participation of people with disabilities by employing socially assistive robotics (SAR), it is critical to develop platforms for cooperation, and more fundamentally, learning in which humans and robots form a community of shared interest and purpose. This is a technical challenge in terms of developing a robust network for performance-enhancing devices and information sharing among intelligent agents - human and robot. The design challenge lies in developing an environment in which users are fully engaged in the 'mixed' learning community, and that is consistent with ethical principles, such as self-determination, interdependence, autonomy, risk, and harm reduction. The community will need to be designed to generate knowledge, tools, protocols and practices that will optimally leverage user capacity in human-robot communities, both the short-term (performance) and long-term (learning). More immediately, the community will need to be embedded in a networked, distributed learning environment that is digital, wireless and 
integrative of all learners, human and non-human - that is users and SAR. Distributed learning refers to both the non-local nature of the learning (online) and the density of the learning (i.e., how it is spaced over time). Distributed learning allows for distant and optimally spaced/paced learning (Son \& Simon, 2012).

\section{Learning Connections and Wireless}

Linking multiple people across physical spaces is not a new idea (Cesar, Kaiser, \& Ursu, 2014). Connected shared experiences were envisioned soon after the telephone's invention in 1876. Since then, academic and industry efforts to achieve immersive group communication have met with varying degrees of success (Chou, 2013). Recent developments include the rapid adoption of video-mediated communication technologies by home users (Kirk, Sellen, \& Cao, 2010) and children reading with long-distance family members via background subtracted video communication (Follmer et al. (2012).

With a wireless infrastructure in place and proof-of-concept studies completed, in depth studies of user experiences were made as a precursor to formal learning studies. The concept of wireless web access is not new. Wireless handheld devices have been explored as nomadic information guides in situations as diverse as science centers, convention centers, transit stations, sports arenas, community centers, public parks, libraries, and museums (Grant, 1993; Abowd et

al., 1997; Rieger \& Gay, 1997; Inkpen, 1999; Cheverst et al. 2000; Jones et al. 2000; Kirk, 2001; Mandryk et al., 2001).

The trend is towards dynamic shared experiences rather than just static interpersonal exchanges (Cesar, Kaiser, Ursu, 2014) for example, learning media that are truly natural and immersive shared experiences such as Google Chat. Video-mediated communication systems must be able to understand the context of the shared activity as well as the social layer of 
interaction. Wireless robots with accuracy in automatic speech recognition designs with various types of representations and features such as extraction techniques, speech classifiers and performance evaluators have been some of the recent advances in communications (Dadwal, 2012). Other robotics and wireless sensor network interactions (Castro, Alqassis, Smith, Ketterl, Sun, Ross, Rosemurgy, Savage \& Gitlin, 2013), wireless operations of industrial robots (Hunt, 2014) are just some examples of integration of wireless technology in robotics in recent years.

\section{Learning Community Properties}

Distributed Learning and Human-SAR Synergies. As ubiquitous and pervasive technology fosters augmentation across domains of human functioning, whether in the guise of genetic engineering, wearable computing or other modalities, a host of questions will be presented to policy makers, technologists, scientists, engineers, lawyers, health care providers, educators and others about what is human (or personhood) in the context of unprecedented, networked capacities. Humans and SAR could participate in synergistic collaborative learning, building upon digital learning models that foster distributed leadership (i.e., Harris, Jone \& Baba, 2013) and distributed intelligence over the lifespan (Fisher \& Konomi, 2007). Digital platforms for online engagement and learning, buttressed by mobile and wireless technologies open the possibility of distributed intelligence, transcending physical barriers of space and place, but also overcoming the limitations of human attention and context awareness as smart technologies expand the scope of human learning synergistically (Fisher \& Konomi, 2007; Harris, et al., 2013).

Wholly artificial systems of distributed intelligence, using a 'smart' peer-learning architecture are in prototype phases today (i.e., Pimple, Saravane \& Gavankar, 2015). Such systems are patterned on human cognitive processes (Pimple, et al., 2015) which suggests that 
future human-intelligent agent architectures for learning networks, including SAR-human learning communities may take the 'next step' of a fully integrated artificial intelligence (SAR)human synergistic learning community. Alternately, SAR-human learning communities may function synergistically without need for full-bore AI; grounded instead in the augmented intelligence of the learners facilitated by autonomous SAR. We foresee both possibilities from our futures perspective. In either case, the result is a community of peer-learning and exchange, transcending human-robot distinctions in a seamless integration. With the human-, non-human hierarchy no longer in play, the ethical perspective on learning both within and across communities of mixed sentience is recast.

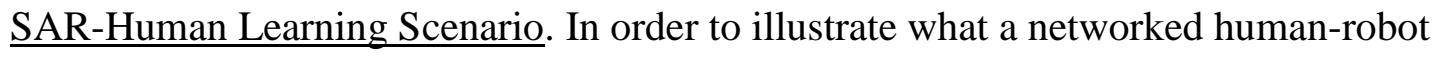
learning community might look like let us consider a plausible scenario based upon the authors' current research project aimed at creating a human-robot learning network prototype. The prototype in development engages only individuals with physical disabilities, absent cognitive, sensory or intellectual disabilities, that require the use of a wheel chair, augmented by a wheel chair-mounted robotic arm. Our goal is for each of three users and their robots to develop unique repertoires of object grasping and motion behaviors, performed by the robot with human (user) inputs as needed or desired, that can be shared either at the initiative of the user(s) or robots in any of the conceivable permutations (human-human, human-robot, robot-human, robot-robot). The augmented capability of the user comes from being able to grasp objects otherwise out of reach or not readily held, but also through the accumulated experiences of robots and users in their daily lives, enhancing not only the stock of knowledge, but also performance of system components, singly or joint, and also the collective as a whole. In addition to obvious benefits of enhanced activities of daily living (ADL) for the users there will also be the benefit of enhanced 
social networks (i.e., shared information, sense of belonging, etc.) and self-efficacy (i.e., mastery of technology and learning networks). For the robots the learning gains will be through enhanced knowledge and performance but also through a kind of situational awareness of ethical issues around sharing information that is personal to the user; a combination of rules and inputs that constrain exchange 'outward' to other users and robots.

The robot first learns from multiple trials with objects of various sizes, configurations and 'settings' (i.e., placements) using algorithms that aim to optimize the response. This is, however, only the beginning because to accomplish its tasks most effectively (from the user standpoint) it must be able to learn from the human as well. Learning from humans is part of collaborative learning schemas that are being developed to piggyback on human intelligence, without requiring constant human intervention. In the case of a robotic arm the human may only need to provide inputs at the end of the behavioral arc, for instance, at a point where the algorithm 'runs out' - imagine a final flourish at the end of a comb sweep encountering hair of different consistencies. For an otherwise autonomous robot to receive direct inputs from humans that can be captured in algorithms the robot must switch to semi-autonomous mode allowing for reinforcement learning originating from the user.

Once configured as a network and engaged in regular exchanges the human-robot network will inevitably differentiate into sub-groups once scaled. Because the nature of information to be exchanged is personal and the stakes for participating in groups for which the learning is a net positive to the user, we anticipate distinct communities of human-robot users emerging of greater or lesser permeability, depending upon the constituents and focus. For example, in domains of physical intimacy, gender or other factors may serve to demarcate communities, while in the domain of sports gender may, or may not, serve as a strong 
demarcation factor. It is not possible to foresee the self-organizing tendencies of future learning communities of humans and robots. It is, however, possible to create higher-level scenarios of learning community exclusivity and inclusivity, as we will here. Before proposing alternate scenarios meant to capture 'learning ecologies' that could differentiate human-robot learning communities in the future, it is important to consider the ethical issues that may underlie their formation and behavior.

\section{Ethical Dimensions}

In the context of a networked human and robot learning-community we may borrow an 'ecosystem' framework the ethical treatment of SAR and human inspired from ethicists critical analyses of human's interactions with nature (i.e., Jax, et al., 2013). Robots, humans and other social agents networked into learning communities could be said to constitute a network in the context of human dependence on non-human actors and relationships. In his five-part taxonomy of "roboethics" Steffen Steinert (2014) makes a compelling case for robots transcending considerations of care due to "instruments", or even as "recipients" of human actions, to take on influential social roles, not as conscious entities acting as "moral agents", but rather as active participants in exchanges of moral consequence. As he notes "... Robots do not cause bas parenting, but they can be used by negligent parents.” (P.255)

In this context, robots and social agents have a moral value, tied minimally to their contribution to human well-being. The effect is to increase the scope of ethical consideration beyond the human actors to include non-human intelligence. Borrowing from a parallel argument about nature posited by Jax and colleagues, given that non-human intelligence is not yet equated with human intelligence, the ethical obligations of humans to SAR may be 'indirect'; that is 
towards the SAR only to the extent that the SAR is valuable to the well-being of the user, rather than in its own right as a peer being (Jax, et al., 2013).

Meanwhile a systems approach to robot-human communities provides a framework for engaging human users and other social agents (SAR and others) in a network that benefits from feedback loops, and adapts to optimal configurations. Such an approach requires that we consider standards of behavior for the constituent parts in a reciprocal, relational context. Standards of behavior inclusive of behavior towards SAR, if not grounded in 'rights' as such, will be required - with the assent of the users. It is not necessary for the SAR to be accorded full personhood, or to operate on an AI platform. Regardless, the networks and embedded communities support the status of SAR as co-creators, rather than as objects acted upon. Such participatory networks will contribute towards building physical and virtual infrastructures of assets, systems and networks to the benefit of all assistive technology (AT) users. Users will become skilled in mixed group learning, but not without careful engineering and design features aimed at the development of experiential learning environments.

\section{Design and Engineering Challenges}

Perhaps the most salient engineering challenge in creating distributed (virtual) AR-user communities lies in generating 'experiential' content and activities to convey complex ideas critical to building and sustaining such communities. For instance, how can SAR and users alike come to a shared "understanding" (i.e., lexical and syntactic referencing) of problems such as how do we overcome geophysical barriers to social participation for people with disabilities?

Immersive learning is particularly robust in conveying experiential learning of some complexity through multimodal learning (De Freitas \& Neumann, 2009). In the service of promoting learning in immersive 'community settings', avatars may be used in the online 
environment for: (a) trust building with non-local users and user communities, (b) ethical problem solving around confidentiality, deciding how to think through dilemmas (share/notshare) in an interactive environment, (c) creating dynamic representations of SAR human capabilities (i.e., the suite of motions for a robotic limb), and (d) immersive confidence-building experiences. Immersive environments can be designed such that barriers to entry, participation and exchange are negligible or non-existent. This is the case because immersive environments generally have an architecture that is developed with every possible user in mind, an approach that is labeled 'universal design.'

Universal Design. Universal design for learning (UDL) is one 'environmental response' to the twin problems of developing online human/robot communities for all and customized learning adaptations. Universal design for learning involves the purposeful design of curriculum and the presentation of information aimed at engaging all learners through ready access and participation in course content and process (Bernacchio \& Mullen, 2007; McGuire, Scott, \& Shaw, 2006). Functionally, the role of UDL resembles that of assistive technologies (AT) inasmuch as the latter is a tool to raise student performance to the 'expected level', although UDL and the instructional technology (IT) that undergirds it supports specific curriculum and pedagogic aims (Parette \& Peterson-Karlan, 2007). Hence, the availability and quality of UDL will be an important mediating factor to evaluate when assessing the potential of SAR user learning environments.

Until UDL becomes a consistent feature of learning communities the usability gap between SAR and learning tools will remain. Closing this gap will require more than technical interface and/or interoperability patches; structural and interpersonal supports that facilitate learning and performance are implicated. This will require problem-solving strategies for 
facilitating online community learning. It is important to identify problem-solving strategies that enhance SAR usability, or its fit, suitability and relevance to diverse end users. It is also important to increase the capacity of the shared learning environments to improve learning for the user with a disability. This is one of the main foci of any preferred future because problemsolving enhancements to the learning environment will expand the scope of user exchange, the favorability of exchange and how generative the learning becomes. These are valued outcomes and augment the user's capabilities; hence, they are ethically positive in terms of furthering the 'good life' of those users.

Consider the technological challenges in a specific use case of people with disabilities employing their personal SAR (a humanoid robot) to assist them in their activities of daily living (ADL) ranging from meals, personal grooming to entertainment and communication. ADLs can vary with the function of the user's personal environment preferences, and even his or her social support network. For instance, some users might need to rely on the help of the robot for tasks that for other users might be assisted by a cohabiting relative or a nurse. The basic unit of learning is thus the human user / SAR pair - the user needs to learn and adapt to the capabilities and limitations of the robot, while the robot must learn the preferences of the user, the particularities of his/her home environment as well as form a model of the habits and disabilities of the user.

From an engineering point of view, this is a very difficult learning setup. Most learning algorithms rely on a trial-and-error feedback loop, where the learned model is reinforced by rewards for successes and penalties for failure. However, in a human user / SAR pair operating in a home environment there is very little tolerance for repeated failures - we cannot expect the 
user to accept dozens of tries with failed ADLs (dropped glasses, spilled food) until the reinforcement learning gets it right (Modares, Ranatunga, Lewis \& Popa, 2015).

Learning communities can provide a way out from this engineering dilemma - by participating as a unit in a learning community, the user / SAR pair can benefit from the aggregated experience of other members. Such vicarious participation in learning, mediated by wireless connectivity and video technology at the user as well as the robot level, can benefit both the human and the robot side of learning. Nevertheless, such a system also presents new technological and human challenges. For instance, communication takes place at two different levels - that of human communication (both linguistic and gestural cues) at the user level and that of computer data languages (such as XML) at the computer level. These are likely to be incomprehensible to the other party (Anzalone, et al., 2013). Another technical challenge is posed by the heterogeneity of users (preferences, disability level), robots (capabilities, hardware design, software) and home environments. A final technological challenge is one that also has ethical, privacy and legal implications. There a critical the difference between the social networking 'preferences' of the human user and the SAR. The SAR can most usefully exchange information with other SARs whose owner's disability and daily environment (i.e., work, home, etc.) most closely matches their own. A shared environment is thus the guiding criterion for exchange from the standpoint of the SAR. Whereas for the human user, shared values, affiliation, community belonging and other non-technical criteria pertaining to trust are more salient.

\section{Gaining Foresight into Possible Futures}

As we prepare to peer ahead into possible futures we venture forth from the familiar social science domains of prediction and control into the domain of the probabilistic for which no hard-and-fast values can be attached. Those probable futures can serve as useful tools for 
decision making as we contemplate different paths forward; all the while acknowledging that no single path can lay claim to 'reality'.

We employed scenario planning for the purposes of collaborative idea building, drawing upon diverse backgrounds, expertise and mental models. We sought out active formats for foundational ideas derived from ongoing interdisciplinary research in the human-robot learning community involving WMRA. To that point, several of the current authors are team members and long-time collaborators on assistive technology and online learning communities with expertise in robotics, computer science, technology policy, and social work. Our scenario preparation was inspired by our current research findings, projected into possible future scenarios. This process included establishing parameters and modeling all the elements, followed by scenario development, selection and refinement and strategic choice-making during which we determined which options appear most robust, yet adaptive (Jetter \& Schweinfort, 2011) .

Three possible futures emerged from this process with differing inclusivity profiles. These profiles reflect a tripartite divide of 'open,' 'closed', and 'middle-range' learning ecologies for humans and other social agents. At one end you will find "vertical integration of technologies", also called the 'nexus' scenario (high openness). On the other end of the continuum, the 'closed' end, the "proprietary and parochial concerns dominate virtual learning exchanges" or 'niche' scenario, is found. Occupying a middle position the "parallel development of virtual learning communities in small worlds network," or 'community of communities' scenario. This community type holds a mid-point on the continuum and possessing attributes of both closed and open learning ecologies. The implications of the continuum for inclusiveness and accessibility are non-linear and nuanced; more openness is not necessarily associated with greater accessibility or inclusiveness. 
Choice and self-determination are key threads in the accessibility and inclusiveness mosaic and operate at several levels concurrently, including conceptualization, design, functioning and relationship. The structure and culture of SAR-user communities and their relationship within the broader ecology will be critical to achieving higher-order accessibility outcomes such as enhanced user capabilities, learning, exchange and employability. Policy and technical actions to foster generative AR-user communities will be discussed, together with a preliminary model of accessibility_ positive AR-user communities in each of the three future scenarios.

Figure 1. Three Possible Learning Community Futures

\begin{tabular}{|c|l|l|}
\hline Vertical Integration & $\begin{array}{l}\text { Parallel Development/Small Worlds } \\
\text { "Nexus" }\end{array}$ & $\begin{array}{l}\text { Proprietary \& Parochial } \\
\text { "Community of Communities" }\end{array}$ \\
\hline
\end{tabular}

\section{Closed/Low Connection to Other Communities}

\section{The SARs Inclusive Community}

As mixed human-machine intelligence becomes ubiquitous as a form of expression, comprehension and action in civil life, the fundamental question of who (or what) should enjoy the full measure of rights and capabilities available through the expansion of human knowledge will come to dominate discourse and politics on resource allocations, access and priorities. In the human-robot learning ecosystem we begin with the premise that there is value in enhancing the capabilities of users with disabilities, and, therefore, learning in this context should be to the benefit of human users. This seems indisputable. However, given that the learning ecosystem is 
comprised of both SAR and humans it is not clear why SAR should not benefit as well, given the valued role and 'space' they occupy in the learning community.

As technological barriers to building human-robot learning communities recede values will come into increasingly sharp relief and relevance, as well protocols for participatory design of such communities. At a basic level this speaks to core values and aims such as building community, open access to learning, equity, human worth (i.e., people do not become redundant) and choice. The robot members of such communities, while initially at least perhaps not participating as directly as human members will, nevertheless influence the learning architecture and dynamics because of the their contribution to the mixed intelligence learning value proposition. As such, inclusive SAR communities could become part of the emergent public discourse on developing new models for participatory, mixed intelligence communities whether characterized by artificial intelligence or intelligence augmentation.

Futures' thinking is solidly grounded in contemporary values and ethics and should reflect outcomes that represent not only what is conceivable - that is, passing the 'plausibility' test - but also reflects emerging and cyclical movements that shape events. As we look towards the future SAR-user communities we see learning dynamics that are continually changing and dynamic in nature, but nonetheless having certain distinct equilibrium points. Those equilibrium points are non-neutral, which is to say that they vary in terms of ethical and value-based assessments of the impact on key stakeholders.

Perhaps the most salient example of such an equilibrium point is the "capability" of users with a disability. The user's capabilities are framed by Amartya Sen in terms of freedom, choice and ability to act. In that light, the "vertical integration of technologies", or 'nexus' future while promising a kind of 'universal' accessibility, is distinctly not the most preferred outcome. This is 
because major ethical concerns of users around confidentiality, privacy and autonomy are challenged by an environment in which the flow of information is unchecked. In other words, the user's capabilities are undermined because of highly consequential constraints on choice imposed by a learning system that honors no boundaries, criteria for inclusion/exclusion or individual preferences. For instance, a highly group (or individual) identified approach to problem solving will be taken and used without attribution, and often without a valid understanding of its nature and use. In other words, there will be misappropriation of learning to the detriment of each community's well-being, as well as degradation of learning as a whole.

On the other extreme, the "proprietary and parochial concerns dominate virtual learning exchanges" or 'niche' future poses threats to the accessibility of wider communities of learners and forecloses possibilities of exchange and self-directed growth. In this future, the capabilities of the users are actually diminished relative to the possibilities inherent in learning community inaccessibility, and the constraints imposed by proportionally greater proprietary influences. A kind of zero-sum mentality prevails and learning exchanges beyond the in-group of communities are viewed as losing propositions. For example, 'adjacent' learning communities while problem solving the same social dilemma will not cooperate out of fear that in sharing solutions - or even approaches - they will undermine the value of their own knowledge and ability to learn. In other words, precluding the generative possibilities of shared knowledge and thereby diminishing the growth horizon of within-community learning.

Most favorable is the "parallel development of virtual learning communities in small worlds network" or 'community of communities' future. This is precisely because it safeguards the interdependence of exchanges in the context of viable communities that poses distinct 'local' norms on the one hand, and the possibility for synergistic gains from common interests and/or 
values on the other. Boundaries are respected and arguably cultivated while targeted exchanges are imbued with merit and sought-after. In other words, this configuration captures the full "flavor" of particular, situated learning, while also reaping the benefits of points of connection.

Such "parallel/community-of-communities" configurations are thus ethic-positive in the context of specific SAR-user groups, while not precluding extra-communal exchanges in the 'third-space' at the intersection of communities. In this third space, new norms reflecting some admixture of the local community norms will take root. Policies that protect the autonomy of local SAR-user communities while also fostering common intersectional 'rules of the road' will be critical to the growth and maturation of those communities and the well-being of their constituents. Policy incentives will need to be developed along the developmental path as SARuser communities come online and begin to interface with other networks of intelligent agents and users. Also important will be private-public initiatives aimed at growing the accessibility SAR-user community while balancing out competing commercial and legislative aims. These initiatives will inform both the higher-order networking goals of optimizing learning resources, and the more immediate goals of users to engage in learning that enhances their capabilities while protecting their autonomy. A future in which people with disabilities can avail themselves of the benefits of wireless connectivity and SAR-user communities, to the full extension of their particular capabilities, and not merely a generic augmented capacity, is one to be fostered by every possible means.

\section{Conclusion}

When considered as a whole, the proposed "parallel/community of community" future for robot and human learners blends the learning purpose of the network together with a communal identity as (joint) learners. Learners in such an environment enjoy a kind of functional parity as 
they recognize not only their own individual learning needs - and rights - but also those of the community and its members. A learning ecosystem will be created in which hierarchical considerations of higher priority learners - whether human or robot - will no longer obtain. Moreover, the learning communities themselves will no longer be characterized along strictly human, or their robot, dimensions. Rather, SAR will augment the capabilities of the humans, so too will the humans augment the capabilities of the SAR. Disability as a functional impairment will lose its meaning in such an environment, just as SAR algorithms as a functional limitation lose theirs. Learning will emerge from a jointly constructed environment of knowledge building and sharing akin to language, with a lexicon that reflects the lived experience of the community, and a syntax that reflects historical patterns of valued preferences and bounded action. Every element of the learning ecosystem will occupy a defined and important niche barring changes to the system's overall balance.

We foresee, over time, an evolution in learning communities into knowledge brokering communities as incomprehensible to us as social media would be to habitués of Victorian era coffee houses. In our day the gap between knowing and doing is frequently lamented with knowing usually outpacing doing, not simply as an implementation issue, but more profoundly as the result of disjunctive constructs for what happens (i.e., doings) and what might be (i.e., knowing) due to limited imagination about possibilities. SAR and their interfaces are today being programmed with algorithms that distill knowing and doing into reinforced experience, allowing for growth, learning and increasing autonomy. In this context, performance is an emergent property arising from both physical and metaphorical interactions with real-world environments. Learning shares the same basic properties of other performances, such as movement through the physical world, albeit with greater complexity and less finite boundaries. 
Hence, by creating human-robot learning communities we are not only augmenting the capabilities of its constituents but also creating a new kind of adaptive 'organism' apprehending and acting upon the world in a unique fashion that will doubtless have profound implications for our futures; human and robot. Just as lexical translations of language fail to capture its essential 'truths' - cultural, historical and political - that define a human tongue, so too is it a miscasting of human-robot learning communities to frame them as mere translational environments for exchanging machine and organic experience. Thus, as we embark on the journey of creating human robot learning communities we will do well to use a dynamic framework that recognizes the fundamentally unpredictable nature of these, as with other, futures, while considering as many possibilities as we can. 


\section{References}

Abascal, J., \& Nicolle, C. (2005). Moving towards inclusive design guidelines for socially and ethically aware HCI. Interacting with Computers, 17(5), 484-505. Retrieved from http://search.ebscohost.com/login.aspx?direct=true \&db=psyh\&AN=2005-10232$\underline{002 \& \text { site }=\text { ehost-live }}$

Abowd, G.D., Atkeson, C.G., Dey, A., Hong, J., Long, S., Kooper, R. \& Pinkerton, M. (1997). Cyberguide: a nomadic context-aware tour guide. ACM Wireless Networks, 3, 421-433.

Alonso-Martin, F., Castro-Gonzalez, A., Luengo, F.J.F.G., \& Salichs, M. A., (2015). Augmented robots dialog system for enhancing human-robot interaction. Sensors, 15(7), 15799-15829.

Anzalone, S.M., Boucenna, S., Ivaldi, S., \& Chetouant, M. (2015). Evaluating the engagement with social robots. International Journal for Social Robotics, 7, 465-478.

Anzalone, G. C., et al. (2013). A low-cost open-source 3-D printing. IEEE Access, 1, 803-810.

Argall, B., \& Billard, A. (2010). A survey of tactile human-robot interactions. Robot. Auton. Syst., 58(10), 1159-1176.

Ballard, R. L. (2009). Granpa's call: Conscience, ethics, and aporias. Qualitative Inquiry, 15(3), 467-482. doi:10.1177/1077800408318279

Bernacchio, C., \& Mullen, M. (2007). Universal Design for Learning. Psychiatric Rehabilitation Journal, 31(2), 167-169.

Bickmore, T. W., \& Picard, R. W. (2005). Establishing and maintaining long-term humancomputer relationships. ACM Transactions on Computer-Human Interaction, 12(2), 293327. Retrieved from http://search.ebscohost.com/login.aspx?direct=true \&db=psyh\&AN=2007-11522$\underline{006 \& \text { site }=\text { ehost-live }}$

Blackman T. (2013). Care robots for the supermarket shelf: a product gap in assistive technologies. Ageing Soc., 1(1), 1-19. 
Bohemia, E., \& Ghassan, A. (2012). Globally networked collaborative learning in industrial design. American Journal of Distance Education, 26(2), 110-125, doi: $10.1080 / 08923647.2012 .663678$

Brady, E. M., Cardale, A., \& Neidy, J.C. (2013). The quest for community in Osher Lifelong Learning Institutes. Educational Gerontology, 39, 627-639.

Brown, D.J., McHugh, D., Standen, P., Evett, L., Shopland, N. and Battersby, S. (2011). Designing location based learning experiences for people with intellectual disabilities and additional sensory impairments. Computers and Education, 56 (1), 11-20.

Buchem, I., Atwell, G., \& Torres, R. (2011). Understanding personal learning environments: Literature review and synthesis through the activity theory lens. In R. Torres, Proceedings on the PLE Conference 2011. Second Conference on Personal Learning Environments. University of Southampton. Southampton, UK.

Cadieux, N., \& Laflamme, R. (2009). Éthique professionnelle et éthique en ingénierie. (French). Relations Industrielles / Industrial Relations, 64(2), 307-325. Retrieved from http://search.ebscohost.com/login.aspx $?$ direct=true \&db=bth\&AN=43167553\&site=ehost$\underline{\text { live }}$

Campbell, B. (2012). Innovative leadership: Insights from a learning technologist. The Quarterly Review of Distance Education, 13(4), 233-240.

Campbell, G. (2006). Education, information technologies and the augmentation of human intellect. Change, 38(5), 26-31.

Carr, W. A., Preston, C. J., Yung, L., Szerszynski, B., Keith, D. W., \& Mercer, A. M. (2013). Public engagement on solar radiation management and why it needs to happen now. Climatic Change, 121(3), 567-577. doi:10.1007/s10584-013-0763-y

Castro, C., Alqassis, A., Smith, S., Ketterl, T, Sun, Y., Ross, S., Rosemurgy, A., Savage, P., \& \& Gitlin, D. (2013). A wireless robot for networked Laparoscopy. IEE Transactions in Biomedical Engineering, 60(4), 930-936. 
Learning Futures with Mixed Sentience

Cesar, P., Kaiser, R., \& Ursu, M. F. (2014). Toward Connected Shared Experiences. IEE, Social Computing /Compute. 0018-9162/14

Chou, P. A. (2013). Advances in Immersive Communication: (1) Telephone, (2) Television, (3) Teleportation. ACM Trans. Multimedia Computing, Comm., and Applications, 9(1-41).

Coeckelbergh, M. (2010). Human development or human enhancement? A methodological reflection on capabilities and the evaluation of information technologies. Ethics and Information Technology. doi: 10.1007/s10676-010-9231-9.

Corner, A., \& Pidgeon, N. (2010). Geoengineering the climate: The social and ethical implications. Environment, 52(1), 24-37. Retrieved from http://search.ebscohost.com/login.aspx?direct=true \&db=a9h\&AN=47697011\&site=ehost$\underline{\text { live }}$

Cummings, M. L. (2006). Automation and accountability in decision support system interface design. Journal of Technology Studies, 32(1), 23-31. Retrieved from http://search.ebscohost.com/login.aspx?direct=true \&db=a9h\&AN=23250695\&site=ehost$\underline{\text { live }}$

Dadwal. N. (2012). Speech recognition by wireless robot. International Journal of Electronics and Computer Science Engineering, 1(3), 925-932.

Davies, D.K., Stock, S. E., Holloway, S., \& Wehmeyer, M. L. (2010). Evaluating a GPS-based transportation device to support independent bus travel by people with intellectual disability. Intellectual and Developmental Disabilities, 48(6), 454-463. http://dx.doi.org.ezproxy.uta.edu/10.1352/ 1934-9556-48.6.454

Dekker, S. W. A., Hancock, P. A., \& Wilkin, P. (2013). Ergonomics and sustainability: Towards an embrace of complexity and emergence. Ergonomics, 56(3), 357-364. Retrieved from http://search.ebscohost.com/login.aspx $?$ direct=true $\& d b=p s y h \& A N=2013-12271-$ $\underline{003 \& \text { site }=\text { ehost-live }}$ 
De Freitas, S., \& Neumann, T. (2009). The use of 'exploratory learning' for supporting immersive learning in virtual environments. Computers \& Education, 52(2), 343-352. Doi:10.1016/j.compedu.2008.09.010.

De Wever, B., van Keer, H., Schellens, T., \& Valcke M. (2010). Structuring asynchronous discussion groups: Comparing scripting by assigning roles with regulation by cross-age peer tutors. Learning and Instruction 5, 349-360.

Domingos, P. (2016). The master algorithm: How the quest for the ultimate learning machine will remake our world. New York: Basic Books.

Educause (2009). Things you should know about personal learning environments. EDUCAUSE Learning Initiative. Retrieved from http://net.educause.edu/ir/ library/pdf/ELI7049.pdf

Feil-Seifer, D. (2014). The tail shouldn't wag the dog: Why modeling dog-human interaction is not ideal for socially assistive robotics. Interaction Studies, 15(2) 195-200.

Ferguson, C. A. (1975). Anthropological linguistics. Anthropological Linguistics 17 (1), 1-14.

Fischer, G., \& Konomi, S. (2007). Innovative socio-technical environments in support of distributed intelligence in lifeline learning. Journal of Computer Assisted Learning, 23, 338350.

Fleischman, A., Levine, C., Eckenwiler, L., Grady, C., Hammerschmidt, D. E., \& Sugarman, J. (2011). Dealing with the long-term social implications of research. American Journal of Bioethics, 11(5), 5-9. doi:10.1080/15265161.2011.560337

Fleming, P., Townsend, E., Lowe, K. C., \& Ferguson, E. (2007). Social desirability influences on judgements of biotechnology across the dimensions of risk, ethicality and naturalness. Journal of Risk Research, 10(7), 989-1003. doi:10.1080/13669870701486913

Follmer, S. et al. (2012). People in Books: Using a FlashCam to Become Part of an Interactive Book for Connected Reading," Proc. ACM 2012 Conf. Computer Supported Cooperative Work, 12, 685-694. 
Frost, C., \& Lumia, A. (2012). The ethics of neuroscience and the neuroscience of ethics: A phenomenological-existential approach. Science \& Engineering Ethics, 18(3), 457-474. doi:10.1007/s11948-012-9388-1

Glannon, W. (2002). Indentity, prudential concern, and extended lives. Bioethics, 16(3), 266266. Retrieved from http://search.ebscohost.com/login.aspx?direct=true\&db=ccm\&AN=2009446985\&site=ehost $\underline{\text {-live }}$

Gouvea, R., Linton, J. D., Montoya, M., \& Walsh, S. T. (2012). Emerging technologies and ethics: A race-to-the-bottom or the top? Journal of Business Ethics, 109(4), 553-567. Retrieved from http://search.ebscohost.com/login.aspx?direct=true \&db=psyh\&AN=2012$\underline{25017-011 \& \text { site }=\text { ehost-live }}$

Grant, W.C. (1993). Wireless Coyote: a computer-supported field trip. Communications of the ACM, 36 (5), 57-59.

Grau, C., Ginhoux, R., Riera, A., Nguyen, T. L., Chauvat, H., Berg, M., et al. (2014). Conscious brain-to-brain communication in humans using non-invasive technologies. Plos One, 9(8), 1-6. doi:10.1371/journal.pone.0105225

Grau, C., Ginhoux, R., Riera, A., Nguyen, T. L., Chauvat, H., Berg, M., et al. (2014). Conscious brain-to-brain communication in humans using non-invasive technologies. Plos One, 9(8), 1-6. doi:10.1371/journal.pone.0105225

Habegger, B. (2010). Strategic foresight in public policy: Reviewing the experiences of the UK, Singapore, and the Netherlands. Futures, 42, pp. 49-58.

DOI: 10.1016/j.futures.2009.08.002

Hackett, E., \& Rhoten, D. (2011). Engaged, embedded, enjoined: Science and technology studies in the national science foundation. Science \& Engineering Ethics, 17(4), 823-838. doi:10.1007/s11948-011-9307-x 
Learning Futures with Mixed Sentience

Harris, A., Jone, M., \& Baba, S. (2013). Distributed leadership and digital collaborative learning: a synergistic relationship? British Journal of Educational Technology, 44(6), 926-939.

Hashim, R., \& Mahamood, F.S. (2014). Humanoid robots for skill augmentation of gifted children: Teachers perceptions and Islamic implications. Procedia Computer Science, 42, 343-350.

Hernández-Montes, E., Gil-Martín, L., \& Segura-Naya, A. (2013). The necessary limits to temptation: The turnkey project. Science \& Engineering Ethics, 19(2), 529-533. doi:10.1007/s11948-011-9336-5

Hill, R. B. (2010). Excellence: The importance of vision and work ethic. Technology \& Engineering Teacher, 70(2), 28-31. Retrieved from http://search.ebscohost.com/login.aspx?direct=true \&db=a9h\&AN=57388145\&site=ehost$\underline{\text { live }}$

Hoffman, S., \& Podgurski, A. (2013). Big bad data: Law, public health, and biomedical databases. Journal of Law, Medicine \& Ethics, 41, 56-60. doi:10.1111/j1me.12040

Holland, T. (2011). The future for research in intellectual disabilities. Journal of Intellectual Disability Research, editorial, 55(1), pp. 1-3. DOI: 10.1111/j.1365-2788.2010.01374.x

Holz, T., Dragone, M., \& O’Hare, G. (2009). Where robots and virtual agents meet: A survey of social interaction research across Milgram's reality-virtuality continuum. International Journal of Social Robotics, 1(1), 83-93. doi: 10.1007/s12369-008-0002-2

Howard, T.J., Culley, S. J. \& Dekoninck, E. (2008). Describing the creative design process by the integration of engineering design and cognitive psychology literature. Design Studies, 29, 160-180. doi:10.1016/j.destud.2008.01.001

Hunt, N.J. (2014). Wireless operation of industrial robots. Control Engineering, 61(7), 40-41.

Huschilt, J., Clune, L. (2012). The use of socially assistive robots for dementia care. Journal of Gerontological nursing, 38(10), 15-19. Doi: 10.3928/00989134-20120911-02. 
Inkpen, K.M. (1999). Designing handheld technologies for kids. Personal Technologies, 3(1), 81-89.

Jax, K., et. al. (2013). Ecosystem services and ethics. Ecological Economics, 93, 260-268.

Jetter, A. \& Schweinfort, W. (2011). Building scenarios with fuzzy cognitive maps: an exploratory study of solar energy. Futures, 43, pp. 52-66. doi:10.1016/j.futures.2010.05.002

Jones, M.L.W., Rieger, R.H., Treadwell, P. \& Gay, G. (2000). Live from the stacks: User feedback on nomadic computers and wireless tools for library patrons. ACM Digital Library. http://www.nomad.cornell.edu/research/stacksrpt.htm

Kartoun, U., Helman, S., \& Edan, Y. (2010). A human-robot collaborative reinforcement learning algorithm. J Intell Robot Syst, 60 (2), 217-239. Doi: 10.1007/s10846-010-9422-y

Keizer, S., Foster, M.E., Wang, Z., \& Lemon, O. (2014). Machine learning for multiparty human-robot interaction. ACM Transactions on Interactive Intelligent Systems, 4(3), 1-32.

Khushf, G. (2007). Open questions in the ethics of convergence. Journal of Medicine \& Philosophy, 32(3), 299-310. doi:10.1080/03605310701397057

Kim, G. H., Jeon, S., Im, K., Kwon, H., Lee, B. H., Kim, G. Y., et al. (2015). Structural brain changes after traditional and robot-assisted multi-domain cognitive training in communitydwelling healthy elderly. PLoS One, 10(4) :e0123251. doi: 10.1371/journal.pone.0123251

Kirk, D.S., Sellen, A., \& Cao, X. (2010). Home video communication: mediating 'Closeness,' Proc. ACM Conf. Computer Supported Cooperative Work, 10, 135-144.

Kirk, J.A. (2001). MUSEpad: providing universal museum access. Spectra, 28 (2), 34-36.

Konnola, T., Scapolo, F., Desruelle, P., \& Mu, R. (2011). Foresight tackling societal challenges: Impacts and implications on policy-making. Futures, 43, pp. 252-264.

DOI:10.1016/j.futures.2010.11.004. 
Krawczyk, E. \& Slaughter, R. (2009). New generation of futures methods. Futures, 42, pp. 7582. Doi:10.1016/j.futures.2009.08.011.

Kuosa, T. (2011). Evolution of futures studies. Futures, 43, pp. 327-336. DOI:10.1016/j.futures.2010.04.001.

Kurzweil, R. (2005). The singularity is near: When humans transcend biology. Penguin Books ISBN-13: 860-1400936764; ISBN-10: 0143037889

Lasota, P.A., \& Shah, J.A. (2015). Analyzing the effects of human-aware motion planning on close-proximity human-robot collaboration. Human Factors: The Journal of the Human Factors and Ergonomics Society [2014 Human Factors Prize Finalist], 57(1), 21-33.

Levy, S. (2016). How Google is remaking itself as a "machine learning first" company. Backchannel, retrieved on 10.5.16 at: https://backchannel.com/how-google-is-remakingitself-as-a-machine-learning-first-company-ada63defcb70\#.r7av7kn91

Löwgren, J. (2007). Inspirational patterns for embodied interaction. Knowledge, Technology \& Policy, 20(3), 165-177. doi:10.1007/s12130-007-9029-1

Mackenzie, R., \& Watts, J. (2011). Robots, social networking sites and multi-user games: using new and existing assistive technologies to promote human flourishing. Tizard Learning Disability Review, 16 (5), 38-47.

Malik, N. A., Yussof, H., Hanapiah, F.A., \& Anne, S. J. (2014). Human Robot Interaction (HRI) between a humanoid robot and children with Cerebral Palsy: Experimental framework and measure of engagement. Biomedical Engineering and Sciences (IECBES), 2014 IEEE Conferences on, 430-435.

Mandryk, R.L., Inkpen, K.M., Bilezikjian, M., Klemmer, S.R., \& Landay, J.A. (2001). Supporting children's collaboration across handheld computers. In extended abstracts of Chi 2001 (Conference on Human Factors in Computing Systems) pp. 255-256. ACM, New York. 
Learning Futures with Mixed Sentience

Mara, M., \& Apel, M. (2015). Science fiction reduces the eeriness of android robots: A field experiment. Computers in Human Behavior, 48, 156-162. Doi: 10.1016/j.chb.2015.01.007

Markoff, J. (2015). Relax, the terminator is far away. The New York Times. Accessed from http://www.nytimes.com/2015/05/26/science/darpa-robotics-challenge-terminator.html

Mauss, M. (1950). The gift. Translated by W. D. Halls. Suffolk, UK: Routlege, 1990.

Mazzoni, E., \& Benvenuti, M. (2015). A robot-partner for preschool children learning English using socio-cognitive conflict. Educational Technology \& Society, 18 (4), 474-485.

McGuire, J., Scott, S., \& Shaw, S. (2006). Universal Design and its application in educational environments. Remedial and Special Education, 27, 166-175.

McKee, M., 2, Schlehofer, D., \& Thew, D. (2013). Ethical issues in conducting research with deaf populations. American Journal of Public Health, 103(12), 2174-2178. doi:10.2105/AJPH.2012.301343

Modares, H., Ranatunga, I., Lewis, F.L., \& Popa, D.O. (2015). Optimized assistive human-robot interaction using reinforcement learning. IEEE Transactions on Cybernetics (online).

Moran, S., Bachour, K., \& Nishida, T. (2015). User perceptions of anthropomorphic robots as monitoring devices. Al and Society, 30 (1), 1-21.

Moyle, W., Cooke, M., Beattie, E., Jones, C., Klein, B., Cook, G., \& Gray, C. (2013). Exploring the effect of companion robots on emotional expression in older adults with dementia: a pilot randomized controlled trial. J Gerontol Nurs., 39(5), 46-53. Doi: 10.3928/0098913420130313-03.

Naveh, Z. (2005). Epilogue: Toward a transdisciplinary science of ecological and cultural landscape restoration. Restoration Ecology, 13(1), 228-234. doi:10.1111/j.1526100X.2005.00028.X 
O'Brien and Calius, (2010). Dielectric elastomer switches for smart artificial muscles. Appl. Phys. A, Mater. Sci. Process, (100) 385-389. DOI 10.1007/s00339-010-5857-z

Parette, H. P., \& Peterson-Karlan, g. R. (2007). Facilitating student achievement with assistive technology. Education and Training in Developmental Disabilities, 42(4), 387-397.

Patokorpi, E. (2009). What could abductive reasoning contribute to human computer interaction? A technology domestication view. PsychNology Journal, 7(1), 113-131. Retrieved from http://search.ebscohost.com/login.aspx?direct=true\&db=psyh\&AN=2009-06809$\underline{007 \& \text { site }=\text { ehost-live }}$

Pearson, Y., \& Borenstein, J. (2011). The intervention of robot caregivers and the cultivation of children's capability to play. Science and Engineering Ethics, 19 (1), 123-137.

Peternel, L., Petric,T., Oztrop E., \& Babic, J. (2014). Teaching robots to cooperate with humans in dynamic manipulation tasks based on multi-modal human-in-the-loop approach. Autonomous Robots, 36 (1), 123-136.

Pimple, O., Saravane, U., \& Gacankar, N. Cognitive learning using distributed artificial intelligence. International Journal of Machine Learning and Computing, 5(1), 7-11.

Rabbitt, S.M., Kazdin, A. E., \& Scassellati, B. (2014). Integrating Socially Assistive Robotics into Mental Healthcare Interventions: Applications and Recommendations for Expanded Use. Clinical Psychology Review, 35, 35-46. doi: 10.1016/j.cpr.2014.07.001

Rieger, R. \& Gay, G. (1997). Using nomadic computing to enhance field study. In proceedings of cscl'97: the second international conference on computer support for collaborative learning (eds. R. Hall, N. Miyake \& N. Enyedy) pp. 215-223. Lawrence Erlbaum and Associates, Mahwah, NJ.

Robots Helping Kids (2015). http://robotshelpingkids.yale.edu/overview. Retrieved February 10, 2015. 
Learning Futures with Mixed Sentience

Ross, A., \& Athanassoulis, N. (2010). The social nature of engineering and its implications for risk taking. Science \& Engineering Ethics, 16(1), 147-168. doi:10.1007/s11948-009-9125-6

Sanborn, L. (2015). The future of academic librarianship: MOOCS and the robot revolution. Information Literacy and Instruction, 55(2), 97-101.

DOI: http://dx.doi.org/10.5860/rusq.55n2.97

Sardar, Z. (2010). The namesake: Futures; futures studies; futurology; futuristic; foresightWhat's in a name? Futures, 42, pp. 177-184. Doi: 10.1016/j.futures.2009.11.001

Savath, V., \& Brainard, S. G. (2013). Managing nanotechnology risks in vulnerable populations: A case for gender diversity. Review of Policy Research, 30(5), 549-565. doi:10.1111/ropr.12031

Seale, J. (2006). Disability, technology and e-learning: Challenging conceptions. Association for Learning Technology Journal, 14(1), 1-8.

Shackleford, W., Cheok, G., Hong, T., Saidi, K., \& Shneier, M. (2016). Performance evaluation of human detection systems for robot safety. J Intell Robot Syst, 83, 85-103. Doi: 10.1007/s10846-016-0334-3

Siemens, G. (2005). Connectivism: A learning theory for the digital age. International Journal for Instructional Technology and Distance Learning. Accessed from http://www.itdl.org/Journal/Jan_05/article01.htm

Siep, L. (2003). Normative aspects of the human body. Journal of Medicine \& Philosophy, 28(2), 171-185. doi:10.1076/jmep.28.2.171.14208

Singh, A., Karanam, S., \& Kumar, D. (2013). Constructive learning for human-robot interaction. IEEE Potentials, 13-19.

Sipiora, M. P. (2012). Introduction to the special section. Humanistic Psychologist, 40(3), 232233. doi:10.1080/08873267.2012.699849 
Snow, C. E., van Eeden, R., \& Muysken, P. (1981). The interactional origins of foreigner talk: Municipal employees and foreign workers. International Journal of the Sociology of Language 28, 81-91.

Song, J.H., Kim, H.M., \& Kolb, J.A. (2009). The effect of learning organizational culture on the relationship between interpersonal trust and organizational commitment. Human Resource Development Quarterly, 20(2), 147-167.

Spahn, A. (2012). And lead us (not) into persuasion...? Persuasive technology and the ethics of communication. Science \& Engineering Ethics, 18(4), 633-650. doi:10.1007/s11948-0119278-y.

Steinert, S. (2014). The five robots: A taxonomy for 'roboethics'. International Journal of Social Robotics, 6 (2), 249-260.

Sardar, Z. (2010). The namesake: Futures; futures studies; futurology; futuristic; foresightWhat's in a name? Futures, 42, pp. 177-184. Doi: 10.1016/j.futures.2009.11.001

Taggart L., Truesdale-Kennedy M., Ryan A. \& McConkey R. (2012). Examining the support needs of ageing family carers in developing future plans for a relative with an intellectual disability. Journal of Intellectual Disabilities 16, 217-234.

Tapus, A., \& Matarić, M.J. (2008). Socially assistive robots: The link between personality, empathy, physiological signals, and task performance. Association for Advancement of Artificial Intelligence Spring Symposium: Emotion, Personality, and Social Behavior, 33140.

Tapus, A.,Matarić, M., \& Scassellati, B. (2007). The grand challenges in socially assistive robotics. IEEE Robotics \& Automation Magazine, 4(1), 35-42.

Thomaz, A. L., \& Breazeal, C. (2008). Teachable robots: Understanding human teaching behavior to build more effective robot learners. Artificial Intelligence, 172, 716-737. 
Learning Futures with Mixed Sentience

Tobos, M. (2011). Rethinking disability in Amartya Sen's approach: ICT and equality of opportunity. Ethics in Information Technology, 13, 107-118.

Uluer, P., Akahn, N., \& Köse, H. (2015). A new robotic platform for sign language tutoring: humanoid robots as assistive game companions for teaching sign language. Int J of Soc Robotics, 7(5), 571-585. doi: 10.1007/s12369-015-0307-X

Vanderburg, W. H. (1989). Professionals and social responsibility: Some patterns. Journal of Business Ethics, 8(2), 209-215. Retrieved from http://search.ebscohost.com/login.aspx?direct=true\&db=bth\&AN=5397524\&site=ehost-live

Waelbers, K. (2009). From assigning to designing technological agency. Human Studies, 32(2), 241-250. doi:10.1007/s10746-009-9117-1

Waelbers, K. (2009). Technological delegation: Responsibility for the unintended. Science \& Engineering Ethics, 15(1), 51-68. doi:10.1007/s11948-008-9098-x

Ward, A., Moon, N., \& Baker, P.M.A. (2012). Functioning, capability and freedom: A framework for understanding workplace disabilities. Employee Responsibility and Rights Journal, 24, 37-53.

Weeks, L. E., Nilsson, T., Bryanton, O., \& Kozma, A. (2009). Current and future concerns of older parents of sons and daughters with intellectual disabilities. Journal of Policy and Practice in Intellectual Disabilities, 6(3), 180-188.

Wehman, P. Chan, F., Ditchman, N., \& Kang, H. (2014). Effect of supported employment on vocational rehabilitation outcomes of transition-age youth with intellectual and development disabilities: a case control study. Intellectual and Developmental Disabilities, 52(4), 296310. Doi: 10/1352/1934-9556-52.4.296

Welling, L. I. L. (2012). Limited sources of normative justification in the secular constitutional state? On the role of religiously motivated arguments in bioethical debates. Jahrbuch Für Wissenschaft Und Ethik, 16(1), 41-64. doi:10.1515/jfwe.2012.41 
Learning Futures with Mixed Sentience

Williamson, T. J. (2010). Predicting building performance: The ethics of computer simulation. Building Research \& Information, 38(4), 401-410. doi:10.1080/09613218.2010.481204

Wise, P. H. (2012). Emerging technologies and their impact on disability. The Future of Children, 22(1), 169-191. Retrieved from http://search.ebscohost.com/login.aspx?direct=true\&db=psyh\&AN=2012-19492$\underline{005 \& \text { site }=\text { ehost-live }}$

Wolbring, G. (2016). Employment, disabled people and robots: what is the narrative in the academic literature and Canadian newspapers? Societies, 6 (15), 1-16. Doi: $10.3390 /$ soc6020015.

Wong, W. K., Chan, T. W., Chou, C. Y., Heh, J. S. \& Tung, S. H. (2003). Reciprocal tutoring using cognitive tools. Journal of Computer Assisted Learning 19, 416-428.

Wu, Y.H., Fassert, C., Rigaud, A.S. (2012). Designing robots for the elderly: Appearance issues and beyond. Archives of Gerontology and Geriatrics, 54, 121-126. 